\title{
Decomposing item-method directed forgetting of emotional pictures: Equivalent costs and no benefits
}

\author{
Tracy L. Taylor ${ }^{1}$ - Chelsea K. Quinlan ${ }^{1}$ - Kelly C. H. Vullings ${ }^{1}$
}

Published online: 6 December 2017

(C) Psychonomic Society, Inc. 2017

\begin{abstract}
Using an item-method directed forgetting task, we presented negative, neutral, and positive photographic pictures, one at a time, each followed by an instruction to remember or forget. We determined that the directed forgetting effect, defined as better subsequent recognition of to-be-remembered (TBR) items than to-be-forgotten (TBF) items, was equivalent across negative, neutral, and positive pictures. To disentangle the underlying costs (i.e., decrease in memory for TBF items) and benefits (i.e., increase in memory for TBR items), we compared recognition memory performance in the directed forgetting task to that of a novel within-subjects rememberall control condition (Experiment 1) and to a between-subjects remember-all control group (Experiment 2). We observed costs without benefits across all three emotions-negative, neutral, and positive - in both experiments. These results demonstrate that equivalent directed forgetting effects for emotional stimuli are not attributable to different underlying component processes. Instead, our results suggest that selection for encoding is accomplished in similar ways, regardless of emotional content.
\end{abstract}

Keywords Item-method directed forgetting $\cdot$ Intentional forgetting $\cdot$ Costs and benefits $\cdot$ Pictures $\cdot$ Emotion

Tracy L. Taylor ttaylor2@dal.ca

1 Department of Psychology and Neuroscience, Dalhousie University, 1355 Oxford Street, PO Box 15000, Halifax, NS B3H 4R2, Canada
Whereas forgetting is often viewed as an inconvenient failure of memory, when performed intentionally, forgetting operates in the service of memory (e.g., Bjork, 1972; Bjork, Bjork, \& Anderson, 1998). Intentional forgetting can operate at different stages of information processing to prevent unwanted items from being encoded into long-term memory and to prevent unwanted representations from being retrieved (see Anderson \& Hanslmayr, 2014, for a review). Distinct mechanisms are engaged to accomplish intentional forgetting at encoding versus retrieval, with control over encoding achieved by a withdrawal and reallocation of processing resources (see below) and control over retrieval achieved by the implementation of inhibitory control (e.g., see Basden, Basden, \& Gargano, 1993; Geiselman, Bjork, \& Fishman, 1983) and/or a shift in mental context (e.g., Sahakyan \& Kelley, 2002). In this study, we were interested exclusively in intentional forgetting that operates to prevent unwanted encoding.

Intentional forgetting at encoding requires that participants exert top-down control over limited-capacity resources to ensure that relevant items are processed and committed to longterm memory, to the relative exclusion of irrelevant items. In the laboratory, this control is elicited using an item-method directed forgetting task (see MacLeod, 1998, for a review). Participants are presented with study items, one at a time, each followed by an instruction to remember or forget. Because the instruction follows the disappearance of each study item (although see Paller, 1990), participants must attend to each item as it is presented and use maintenance rehearsal to refresh the item representation in working memory until the memory instruction is presented (e.g., Gardiner, Gawlik, \& Richardson-Klavehn, 1994; Hsieh, Hung, Tzeng, Lee, \& Cheng, 2009; Paz-Caballero, Menor, \& Jiménez, 2004). If 
the instruction is to remember, participants engage in elaborative rehearsal to commit the to-be-remembered (TBR) item to long-term memory. If the instruction is to forget, participants engage frontal control mechanisms (Bastin et al., 2012; Hauswald, Schulz, Iordanov, \& Kissler, 2010; van Hooff \& Ford, 2011; Wylie, Fox, \& Taylor, 2008; Yang et al., 2013) to actively withdraw processing resources from the to-beforgotten (TBF) item representation (Fawcett \& Taylor, 2010, 2012; Taylor, 2005; Taylor \& Fawcett, 2011; Thompson, Hamm, \& Taylor, 2014; see also Rizio \& Dennis, 2013). This withdrawal of processing resources is believed to cease further covert rehearsal of the unwanted item (e.g., Hourihan \& Taylor, 2006) while possibly also redirecting limited-capacity resources to cumulative rehearsal of preceding TBR items. The result of this active cognitive control (Fawcett \& Taylor, 2008; Cheng, Liu, Lee, Hung, \& Tzeng, 2012) is that TBR items receive more rehearsal than TBF items and are therefore more likely to be encoded into long-term memory and to be represented with greater fidelity (Fawcett, Lawrence, \& Taylor, 2016). Consequently, there is greater subsequent recognition of TBR items than TBF items, a difference referred to as a directed forgetting effect.

Although a majority of item-method directed forgetting studies have used words as stimuli, Quinlan, Taylor, and Fawcett (2010) determined that directed forgetting effects occur both within and across stimulus types. In a fully factorial design, they presented at study and test coloured line drawings of objects (e.g., picture of a kite) or the corresponding verbal referents to those objects (e.g., the word kite). Thus, across study-test phases, the conditions included picture-picture, picture-word, word-word, and wordpicture. While the picture superiority effect conferred overall greater subsequent recognition for pictures compared to words presented at study, there was nevertheless a significant directed forgetting effect for all four study-test combinations. Demonstrating tremendous flexibility in cognitive control over the contents of memory, directed forgetting effects have likewise been obtained using phone numbers (Gottlob, Golding, \& Hauselt, 2006), complex coloured photographs (Hauswald \& Kissler, 2008), human face stimuli (Goernert, Corenblum, \& Otani, 2011; Quinlan \& Taylor, 2014), abstract symbols (Hourihan, Ozubko, \& MacLeod, 2009), and visual depictions of mathematical roulette curves (Fawcett et al., 2016). Such generalizability speaks to the purported role of directed forgetting in everyday memory.

Given that a directed forgetting effect likely reflects the operation of a general cognitive mechanism used to restrict the unwanted encoding of irrelevant items, an obvious question is whether the efficacy of this control in normal cognition is impacted by negative emotion. On the one hand, memory is enhanced for negative words (e.g., Kensinger \& Corkin, 2003; Ochsner, 2000) and pictures (e.g., Dolcos \& Cabeza, 2002; Hamann, Ely, Grafton, \& Kilts, 1999). This raises the question of whether negative items are therefore relatively more difficult to forget. On the other hand, actively limiting unwanted encoding depends on patterns of neural activation that are distinct from those used to remember (e.g., Rizio \& Dennis, 2013; Wylie et al., 2008). This implies that intentional forgetting is not simply the obverse of intentional remembering and need not necessarily be impacted by the same stimulus conditions that influence remembering. It is therefore not a foregone conclusion that intentional forgetting in an itemmethod task should be reduced or eliminated for negative items.

The question of whether directed forgetting effects are reduced for negative compared to neutral words has received extensive study but has no clear answer. In part, this is due to considerable variability in both the operationalization of "negative" and in the selection of study populations. Negative words may be denotative (e.g., the word sad), connotative (e.g., the word failure), and/or evocative (e.g., taboo words) and have been selected as study items based on negative valence per se (e.g., Bailey \& Chapman, 2012; Brandt, Nielsen, \& Holmes, 2013; Cloitre, Cancienne, Brodsky, Dulit, \& Perry, 1996; Patrick, Kiang, \& Christensen, 2015; Wong \& Moulds, 2008), because they are threat-related or traumarelated (e.g., Elzinga, de Beurs, Sergeant, van Dyck, \& Phaf, 2000; Elzinga, Phaf, Ardon, \& van Dyck, 2003; McNally, Clancy, \& Schacter, 2001; McNally, Metzger, Lasko, Clancy, \& Pitman, 1998; McNally, Otto, Yap, Pollack, \& Hornig, 1999;Moulds \& Bryant, 2002), or because they are relevant to a specific psychopathology (e.g., Korfine \& Hooley, 2000; Liang, Hsu, Hung, Wang, \& Lin, 2011; Tolin, Hamlin, \& Foa, 2002). This variability in the definition of "negative" reflects the fact that the majority of studies have been aimed at elucidating memory control mechanisms underlying clinical disorders, vulnerabilities, and/or individual differences variables that have clinical relevance. For example, such studies have examined effects of negative emotion on directed forgetting in obsessive-compulsive patients (Wilhelm, McNally, Baer, \& Florin, 1996) compared to both anxious and nonanxious controls (Tolin et al., 2002); individuals with dissociative identity disorder (Elzinga et al., 2003); individuals with high and low dissociative style (Elzinga et al., 2000); individuals reporting repressed or recovered memories of childhood sexual abuse (McNally et al., 2001); high and low dysphoric participants (Wong \& Moulds, 2008); individuals with borderline personality disorder (Cloitre et al., 1996; Korfine \& Hooley, 2000); women with abuse histories, either with or without posttraumatic stress disorder (McNally et al., 1998); acutely traumatised individuals with or without acute stress disorder (Moulds \& Bryant, 2002); patients with schizophrenia (Patrick et al., 2015); individuals with panic disorder (McNally et al., 1999); and socially anxious individuals 
(Liang et al., 2011). It is perhaps not surprising that there is no clear understanding of when, whether, and how negative emotion-broadly defined-influences item-method directed forgetting.

Unfortunately, the results are not necessarily clear-cut even after restricting consideration to "normal" adult samples ${ }^{1}$ for whom "negative" words are selected based on rated valence (rather than relevance to a clinical condition) or after distinguishing effects of valence and arousal. For example, Brandt et al. (2013) observed larger magnitude directed forgetting effects for negative words compared to less arousing neutral words - albeit due to increased recognition of negative versus neutral TBR items rather than because of decreased recognition of TBF items (see their Table 1). In contrast, Bailey and Chapman (2012) showed smaller directed forgetting effects in recognition for both positive and negative words that were matched to each other on arousal, compared to less arousing neutral words. While this suggests that arousal (independent of negative/positive valence) limits intentional forgetting of words, Bailey and Chapman (2012) used a nonstandard task that presented memory cues simultaneously with the study words (similar to Paller, 1990). Using a more typical directed forgetting task, Gallant and Yang (2014) reported that an effect of emotion on directed forgetting is not observed in normal young adults when positive and negative words are selected to be only as arousing as neutral words. Although this does not explicitly corroborate an effect of arousal on directed forgetting, it does appear to rule out an effect of valence. That said, Gallant and Dyson (2016) found smaller directed forgetting effects for negative words compared to less arousing neutral words, but also compared to positive words that were matched at both low and high levels of arousal, thus evidencing an effect of negative valence per se, independent of arousal. Altogether, the conclusion is that directed forgetting of negative words is sometimes larger, sometimes smaller, and sometimes no different than neutral words, and when it is different, this may be due to negative valence per se and/or higher levels of arousal.

Compared to words, one might argue that photographic images better reflect the kinds of emotional mental images that prompt real-life attempts to intentionally forget; are likely to be more emotionally evocative (e.g., consider the difference between the subjective emotional impact of a colour photographic image of the aftermath of armed conflict vs. the word war); and, on both counts, have relatively more ecological

\footnotetext{
${ }^{1}$ This does not necessarily include participants who are selected to serve as "normal healthy controls" in studies that target specialised populations. This is because control group participants are often selected based on exclusion criteria (such as not having a history of the disorder or individual differences variable of interest) or on inclusion criteria (such as being low on a clinical measure, trait, or individual differences variable of interest) that do not otherwise apply to the young adult samples that tend to be drawn from university populations in the study of "normal" cognition.
}

validity. On these grounds, it is surprising that relatively few studies have employed photographic images in the attempt to determine whether negative emotion limits intentional forgetting at encoding. This likely reflects the fact that studies of clinical interest have formed the core literature on the effects of emotion on directed forgetting and that photographic images are less easily manipulated to conform to the varying definitions of "negative" that are required in the study of specialised populations.

Of the few studies that have examined directed forgetting effects for negative compared to neutral pictures in normal adult populations (see note 1 ), the evidence is as mixed as it is when words are employed. For example, there is evidence that directed forgetting effects are smaller for negative pictures than for less arousing neutral pictures (e.g., Hauswald et al., 2010; perhaps also Nowicka, Marchewka, Jednorog, Tacikowski, \& Brechmann, 2010) but equivalent to arousalmatched neutral pictures (Yang et al., 2012). Although this suggests that arousal, rather than valence, is responsible for reducing intentional forgetting of negative pictures, Otani et al. (2012) observed significant directed forgetting effects for both neutral and positive pictures but not for negative pictures that were arousal-matched to the positive pictures. This hints that negative valence per se can also limit control over the encoding of pictorial stimuli. But this interpretation is complicated by the fact that Otani et al.'s pictures could be described using only a single word or phrase. This was a motivated feature that allowed them to test directed forgetting effects in recall rather than recognition but makes it unclear whether their findings reflect reduced encoding control over negative pictures and/or reduced encoding control over their negative verbal descriptors.

Having recently discovered that directed forgetting of human face stimuli is unaffected by whether those faces display angry, neutral, or happy expressions (Quinlan \& Taylor, 2014), we thought it worthwhile to further examine the question of whether negative emotion limits the ability to intentionally forget complex photographic images that have been created to elicit an emotional response. Similar to faces, such images are unlikely to rely primarily on verbal rehearsal and encoding mechanisms; in contrast to faces, they are unlikely to recruit specialised neural circuitry dedicated to their processing (e.g., Kanwisher, McDermott, \& Chun, 1997). Given that the literature to date has produced mixed results, rather than focus on determining whether there is an effect of emotion on the magnitude of the directed forgetting for pictures, our study expanded on the existing literature by determining where such effects occur with respect to the component processes that give rise to the behavioural measurement of directed forgetting.

The fact that the directed forgetting effect in behaviour is measured as a relative difference in subsequent memory performance for TBR and TBF items means that the magnitude 
of this effect can be impacted by a decrease in memory for TBF items (known as the costs of directed forgetting) and/or an increase in memory for TBR items (known as the benefits of directed forgetting; see MacLeod, 1998; Sahakyan \& Foster, 2009). Comparing directed forgetting effects across emotional stimuli thus confounds separable effects that emotion could potentially have on the underlying costs and benefits: Even apparently equivalent overall directed forgetting effects for negative and neutral pictures could be due to different effects of emotion on the constituent processes.

Separating the directed forgetting effect into costs and benefits necessarily depends on finding an appropriate baseline measure against which to assess costs to TBF items and benefits to TBR items (see Jonides \& Mack, 1984, for a discussion of similar issues in separating costs and benefits of attentional cueing effects). This is usually accomplished by testing subsequent memory in a separate group of participants who are instructed to remember all of the study items rather than only half (see Sahakyan \& Foster, 2009; Taylor \& Fawcett, 2012). The costs of directed forgetting are defined as the difference in subsequent memory performance for TBF items under the typical directed forgetting manipulation (hereafter referred to as the forget-half group) compared to the remember-all group. The notion is that success in forgetting according to intention will be reflected in the "cost" to memory for those items that participants were instructed to intentionally forget - precisely because participants intentionally limit the encoding of these items to memory. The benefits of directed forgetting are defined as the difference in subsequent memory performance for TBR items under the typical directed forgetting manipulation (i.e., in the forget-half group), compared to the remember-all group. A benefit occurs to the extent that participants remember proportionally more TBR items in the forget-half group than in the remember-all group. Note that the terms costs and benefits are not evaluative but merely reflect the impact of the memory instruction on performance, with costs to TBF items due to the intention to forget and benefits to the remaining TBR items due to their relative monopoly over processing resources for commitment to memory.

Whereas other published studies in the literature have employed a between-subjects remember-all baseline (e.g., Sahakyan \& Foster, 2009; Taylor \& Fawcett, 2012), we thought it would be preferable to have participants serve as their own controls. Thus, in Experiment 1 we calculated costs and benefits of directed forgetting for negative, neutral, and positive pictures using a novel within-subjects comparison of forget-half and remember-all performance. This was accomplished by dividing the study trials into two blocks. In one block of trials, participants were instructed to remember a random half of pictures of each emotional valence and to forget the other half (hereafter, the forget-half condition). In another block of trials, participants were instructed to remember all of the pictures (hereafter, the remember-all condition).
A yes-no recognition test followed directly after each block of trials; it intermixed the studied pictures from the immediately preceding block of study trials with an equal number of unstudied negative, neutral, and positive foil items. ${ }^{2}$ Although we were primarily interested in the question of whether costs and benefits are influenced differently by negative versus neutral pictures, we included positive pictures to help distinguish between the effects of negative valence per se versus heightened arousal.

To make contact with the wider literature, in Experiment 2 we adopted the more typical between-subjects method of testing both a forget-half group and a remember-all group (see also Sahakyan \& Foster, 2009; Taylor \& Fawcett, 2012). Participants in the forget-half group were shown negative, neutral, and positive photographic pictures, one at a time, each followed with equal probability by an instruction to remember or forget. Participants in the remember-all group were presented with the same pictures but were instructed to commit all items to memory. Following the study trials, participants in both groups completed a yes-no recognition test in which they were asked to distinguish studied items (irrespective of the memory instruction) from unstudied negative, neutral, and positive foil items.

Our primary goal in both experiments was to determine whether negative emotional valence impacts the costs and/or benefits of directed forgetting relative to neutral valence.

\section{Experiment 1}

Experiment 1 used a novel within-subjects design in which participants studied negative, neutral, and positive pictures in the context of both a forget-half condition and a remember-all control condition.

\section{Method}

\section{Participants}

A total of 36 students from Dalhousie University participated in Experiment 1. All participants were tested individually in a

\footnotetext{
${ }^{2}$ Even though directed forgetting effects can also be obtained in recall tasks, we opted for several reasons to test memory using a recognition task. First, our complex pictorial stimuli were not necessarily amenable to, or distinguished by, simple verbal labels or nonidiosyncratic descriptors. Second, by not requiring participants to label or describe pictures, we also guarded against imposing an encoding modality or strategy. Finally, the need to avoid ceiling effects in recognition performance meant that we could present many more trials than might otherwise be possible using a recall task, thus ensuring a wide sampling of negative, neutral, and positive pictures and increasing generalisability of our results.
} 
single session lasting about 60 minutes and received psychology course credit in exchange for their participation. All participants reported normal or corrected-to-normal vision and a good understanding of the English language.

\section{Stimuli and apparatus}

PsyScope X (http://psy.ck.sissa.it; cf. Cohen, MacWhinney, Flatt, \& Provost, 1993) was used to conduct the experiment on a 24-in. iMac computer (Mac OSX) with a standard Macintosh Universal Serial Bus keyboard and Sony MDRXD100 stereo headphones. The stimuli were presented on a uniform white field. The experiment instructions as well as the fixation point ("+") that were presented at the beginning of each trial in the study blocks were printed in black Times New Roman font. In both the study and test blocks, the coloured photographic stimuli were presented in the center of the computer monitor within an invisible port measuring $8^{\circ} \times 7^{\circ}$ of visual angle, as measured from a distance of $57 \mathrm{~cm}$. The memory instructions consisted of high-frequency and lowfrequency tones $(1170 \mathrm{~Hz}$ and $260 \mathrm{~Hz}$, respectively) played over the headphones. At recognition, responses were displayed in the bottom center of the computer monitor within in a black six-point rectangle measuring $3^{\circ} \times 2^{\circ}$ of visual angle.

A total of 288 photographic stimuli were drawn from the International Affective Picture System (IAPS) database and were categorised into three groups of 96 pictures each, based on reported ratings of emotional valence (Lang, Bradley, \& Cuthbert, 2005). Our groupings are referenced in Appendix A according to the numerical picture identity used to name each photograph in the IAPS database. Where the original database includes ratings of valence on a 1-point to 9-point scale, with 1 representing negative valence and 9 representing positive valence, we performed a one-way analysis of variance (ANOVA) to confirm that our three picture collections differed significantly, $F(1,95)=1693.98, M S E=.25, p<.01$. The valence rating for negative pictures $(M=2.92, S D=0.58)$ was significantly lower than for neutral pictures $(M=4.97, S D$ $=0.34), t(95)=29.47, p<.01$, which was significantly lower than for positive pictures $(M=7.11, S D=0.57), t(95)=32.02$, $p<.01$. There were also differences in the overall levels of arousal, $F(1,95)=141.25, M S E=0.71, p<.01$. Given that highly arousing positive pictures tend to contain graphic sexual content and were therefore deemed inappropriate to use in this study, our collection of negative pictures $(M=5.26, S D=$ 0.83 ) were not only significantly more arousing than the neutral pictures $(M=3.27, S D=0.71), t(95)=17.21, p<.01$, they were also significantly more arousing than the positive pictures $(M=4.61, S D=0.98) t(95)=5.08, p<.01$. Importantly, the positive pictures were nevertheless significantly more arousing than the neutral pictures, $t(95)=11.32, p<.01$.
Even though we were not primarily interested in the effects of positive pictures on directed forgetting and could not perfectly equate their arousal levels with those of the negative pictures, we included the positive stimuli to help distinguish effects of valence from effects of arousal. By including positive pictures that were more arousing than the neutral pictures (even if not as arousing as the negative pictures), we could distinguish effects of valence from effects of arousal on the following bases. We could posit a role for negative valence per se to the extent that the negative pictures produced results different from the neutral pictures while at the same time the positive pictures (despite being relatively more arousing) produced results similar to the neutral pictures. Conversely, we could posit a role for arousal to the extent that the positive and negative pictures - both of which were more arousing than the neutral pictures - produced results similar to one another and different from the neutral pictures.

Prior to collecting data from each participant, custom software was used to randomly divide each of the 96 negative, 96 neutral, and 96 positive pictures into unique subsets. For the forget-half condition, 16 negative, 16 neutral, and 16 positive pictures were presented as TBR items in the study block; 16 negative, 16 neutral, and 16 positive pictures were presented as TBF items in the study block; and 32 negative, 32 neutral, and 32 positive pictures were presented as unstudied foils in the test block. For the remember-all condition, 16 negative, 16 neutral, and 16 positive pictures were to be committed to memory in the study block; 16 negative, 16 neutral, and 16 foil pictures were presented as unstudied foils in the test block. In this way, every negative, neutral, and positive item had equal opportunity to be presented as a TBR item, a TBF item, a remember-all item (dummy coded as TBR or TBF), a foil to the forget-half study items, and a foil to the remember-all study items. We performed this randomisation anew before every participant to ensure unique stimulus combinations across our conditions.

\section{Procedure}

Following informed consent, participants were presented with verbal instructions that were later reiterated on the computer monitor. Because condition was defined by whether the study trials intermixed TBR and TBF items (forget half) or else presented only TBR items (remember all), it was necessary to block these conditions at study. We elected to likewise block the recognition test trials such that each test was presented immediately after the corresponding study phase. This was intended to encourage participants to rehearse only TBR items from the given block rather than cumulatively rehearsing TBR items across both blocks, as would likely happen if both study blocks were presented before recognition was tested for either. Thus, participants were informed that they were going to be presented with a block of study trials, followed by 
a recognition test, and then by a second block of study trials, followed by another recognition test. They were informed that each recognition test pertained only to the immediately preceding study block.

Participants were told that each trial in a study block would begin with a small "+" at the centre of the computer monitor, and that this would be replaced by a picture to which they needed to attend. After each picture disappeared, they were informed that they would hear a tone played over the headphones. Half of the participants were presented with the forget-half condition before the remember-all condition; this order was reversed for the other half of the participants. For half of the participants within each block order (i.e., forget half/remember all, remember all/forget half), the highfrequency tone served as the instruction to remember and the low-frequency tone served as the instruction to forget; the tone designation was reversed for the other half of participants. In the remember-all condition, the same tone used as the instruction to remember in the forget-all condition followed the study picture on every trial (e.g., if a high tone designated a TBR picture and a low tone designated a TBF picture in the forgethalf condition, a high tone was presented on every trial of the remember-all condition); this was done to ensure that the tone was used consistently across both blocks of study trials.

Familiarisation phase To familiarise participants with the high and low tones and their associated meanings, 10 familiarisation trials preceded the first study block. Five trials presented the high tone and five trials presented the low tone; these trials were intermixed randomly. On each familiarisation trial, a verbal descriptor of the memory instruction appeared for 3,000 ms. Following a 2,000 ms delay, the corresponding tone was played through the headphones for $400 \mathrm{~ms}$.

Study Block 1 Following the last trial in the familiarisation phase, participants were presented with instructions to describe the nature of the upcoming study block and then with either the forget-half block of study trials or the remember-all block of study trials. At the start of each trial in the study block, the computer monitor remained blank for $800 \mathrm{~ms}$. Then, the fixation stimulus ("+") appeared in the middle of the computer monitor and remained visible for 1,000 ms. This fixation stimulus was removed simultaneously with the appearance of a negative, neutral, or positive picture, which remained visible for $1,000 \mathrm{~ms}$. The monitor was cleared for $200 \mathrm{~ms}$, and then either a high or low tone played for $400 \mathrm{~ms}$ over both channels of the stereo headphones. For the forgethalf condition, tone selection was determined by whether the randomly selected item was part of the TBR or TBF picture set; for the remember-all condition, tone selection on every trial corresponded with the remember instruction (i.e., according to the counterbalancing of high and low tones to remember and forget instructions across participants). The tone was followed by a 1,400 ms intertrial interval during which the computer monitor remained blank. The total duration of each study phase trial was $4,800 \mathrm{~ms}$.

Test Block 1 Immediately following the end of the first study block, participants were presented with instructions for completing a yes-no recognition test. These instructions remained visible at the top of the computer monitor throughout the test block.

The test block presented the negative, neutral, and positive pictures from the immediately preceding study block, randomly intermixed with an equal number of unstudied negative, neutral, and positive foil pictures. Pictures were presented one at a time in the middle of the computer monitor. Participants were instructed to indicate whether or not they recognised the picture from the study phase, irrespective of the associated memory instruction in the case of the forgethalf condition. The participant provided a yes or no response by depressing the $y$ or $n$ key on the computer keyboard, respectively. The response appeared in a black outline text box displayed in the lower half of the computer monitor. Keyboard input could be self-corrected by depressing the delete key and reentering a response. Participants depressed the spacebar to accept the keyboard input, clear the text box, and proceed to the next trial. There was no time limit for inputting a response.

Study Block 2 After completing their first test block, participants completed whichever study block had not already been presented. None of the pictures in the second study block had been presented in the first study block or as foils in the first test block.

Test Block 2 Participants then completed a second yes-no recognition task that intermixed negative, neutral, and positive pictures from the second study block with an equal number of unstudied negative, neutral, and positive foil pictures. None of the foil items presented in the second test block had been presented in either of the study blocks or in the first test block.

Data analysis Trial data were collated using R Studio 1.0.143 running R 3.4.0 (R Core Team, 2017). Various R packages were utilised, including plyr (Wickham, 2011), dplyr (Wickham \& Francois, 2016), tidyr (Wickham, 2017b), and stringr (Wickham, 2017a). We used the R package ez 4.4-0 (Lawrence, 2016) to calculate descriptive statistics (ezStats) and within-subjects analyses of variance (ezANOVA), and to create plots (ezPlot) that were subsequently modified using ggplot2 (Wickham, 2009).

Unlike null hypothesis testing which can only reject or fail to reject a null hypothesis, a Bayesian approach allowed us to compare the weight of evidence that our data provided in support of the null hypothesis versus the alternative hypothesis (see Kruschke \& Liddell, 2017). As 
such, we used the output from ezANOVA to generate a Bayesian information criterion (BIC) approximation to Bayesian posterior probabilities according to the method described by Masson (2011). We accomplished this by implementing in $\mathrm{R}$ the formulae contained in the spreadsheet that Masson provided as supplementary material. We will use the convention $p \mathrm{H} 0$ to refer to the approximated posterior probability of the null hypothesis given the data and $p \mathrm{H} 1$ to refer to the approximated posterior probability of the alternative hypothesis of a nonzero effect. Using Masson's method, the values of $p \mathrm{H} 0$ and $p \mathrm{H} 1$ sum to 1 . Thus, values of $p \mathrm{H} 0=p \mathrm{H} 1=0.50$ are interpreted as providing support for neither hypothesis. Increasing support for one hypothesis over the other occurs as the corresponding probability approaches one (and, conversely, as the other probability approaches zero). In this way, decisions are not binary but relative: We can determine how much support our data provide for a nonzero effect versus how much support they provide for the null hypothesis of no effect. To reduce redundancy in our reporting and in light of the fact that $p \mathrm{H} 0$ and $p \mathrm{H} 1$ sum to 1 , we will report only the larger of the two probabilities. Because it is wordy to describe $p \mathrm{H} 0>0.50$ in terms of "support for the null hypothesis of no effect," we will describe our results in terms of support for an effect when H1 is the larger probability (i.e., $p \mathrm{H} 1>0.50$ ) and against an effect when $\mathrm{H} 0$ is the larger probability (i.e., $p \mathrm{H} 0>0.50$ ). To relate our decisions for or against an effect of interest, we will apply verbal descriptors using the conventions recommended by Raftery (1995), where probabilities $0.50-0.75$ provide weak evidence; probabilities $0.75-0.95$ provide positive evidence; probabilities $0.95-0.99$ provide strong evidence; and, probabilities $>0.99$ provide very strong evidence.

\section{Results}

A hit was defined as a yes response to TBR and TBF items (actual or dummy coded); a false alarm was defined as a yes response to unstudied foil items. These data are shown in Table 1 for the forget-half and remember-all conditions, as a function of emotion. To provide a measure of recognition accuracy corrected for guessing, we subtracted on a subjectby-subject basis the mean proportion false alarms from the mean proportion TBR and TBF hits, separately for each combination of emotion (negative, neutral, positive) and condition (forget half, remember all). ${ }^{3}$ The mean corrected hit rates are shown in Fig. 1.

\footnotetext{
3 There were not any systematic differences in false alarm rates as a function of condition and/or emotion. Indeed, an analysis of false alarm rates revealed positive evidence against a difference in false alarms across condition, $p \mathrm{H} 0$ $=0.86$, strong evidence against an effect of emotion, $p \mathrm{H} 0=0.97$, and strong evidence against an interaction of emotion with condition, $p \mathrm{H} 0=0.98$.
}

Before proceeding to our primary analyses, we first analysed corrected hit rates in the remember-all control condition, as a function of emotion (negative, neutral, positive). This analysis revealed strong evidence against an effect of emotion, $p \mathrm{H} 0=0.96$. This indicates that in a block that required participants to commit all items to memory, there was no inherent advantage for recognizing emotional pictures compared to neutral pictures. In other words, there was no evidence of emotional memory enhancement.

We then analysed the corrected hit rates in the forget-half group, as a function of memory instruction (TBR, TBF) and emotion (negative, neutral, positive). This analysis provided very strong evidence for an effect of memory instruction, $p \mathrm{H} 1$ $>0.99$, consistent with an overall directed forgetting effect (i.e., better memory for TBR than TBF items). However, there was strong evidence against a main effect of emotion, $p \mathrm{H} 0=$ 0.98 , and strong evidence against an interaction of memory instruction and emotion, $p \mathrm{H} 0=0.96$. In other words, there was a robust directed forgetting effect in the forget-half condition (i.e., better recognition of TBR than TBF items), the magnitude of which was not influenced by emotion.

To examine costs to memory of instructing participants to forget half of the items they were later asked to recognise, we analysed the corrected recognition hits for TBF items (actual or dummy coded) as a function of condition (forget-half, remember-all) and emotion (negative, neutral, positive). Our data provided very strong evidence for a difference in overall accuracy as a function of condition, with TBF items recognised at a higher rate when these were dummy-coded trials from the remember-all condition than when they were items that participants were actually instructed to forget, $p \mathrm{H} 1>0.99$. There was, however, strong evidence against an effect of emotion on TBF item recognition, $p \mathrm{H} 0=0.97$, and against an interaction of group and emotion, $p \mathrm{H} 0=0.98$. In other words, there were costs to memory of being instructed to forget items that participants were later asked to recognise (i.e., TBF items showed overall lower recognition in the forget-half condition than in the remember-all condition), but these costs did not vary by emotion.

To assess benefits, we analysed corrected recognition hits for TBR items (actual or dummy coded) as a function of condition (forget half, remember all) and emotion (negative, neutral, positive). Our data provided positive evidence against an effect of condition, $p \mathrm{H} 0=0.86$, indicating that there were no benefits to TBR item recognition. There was also strong evidence against an effect of emotion on TBR item recognition, $p \mathrm{H} 0=0.96$, and strong evidence against an interaction of condition with emotion, $p \mathrm{H} 0=0.98$. In other words, there were no overall memory benefits for the TBR items as a result being allowed to forget half of the studied items versus having to remember them all, and no influence of emotion on benefits. 
Table 1 Experiment 1: Mean proportion hit rates to to-be-remembered (TBR) and to-be-forgotten (TBF) items and mean proportion false alarms to foil items, as a function of emotion (negative, neutral, positive) and condition (forget half, remember all)

\begin{tabular}{|c|c|c|c|c|c|c|c|c|c|}
\hline & \multicolumn{3}{|l|}{ Negative } & \multicolumn{3}{|l|}{ Neutral } & \multicolumn{3}{|l|}{ Positive } \\
\hline & TBR & TBF & Foil & TBR & $\mathrm{TBF}$ & Foil & TBR & TBF & Foil \\
\hline Forget half & $\begin{array}{l}0.826 \\
(0.005)\end{array}$ & $\begin{array}{l}0.694 \\
(0.006)\end{array}$ & $\begin{array}{l}0.071 \\
(0.002)\end{array}$ & $\begin{array}{l}0.841 \\
(0.005)\end{array}$ & $\begin{array}{l}0.699 \\
(0.006)\end{array}$ & $\begin{array}{l}0.074 \\
(0.002)\end{array}$ & $\begin{array}{l}0.807 \\
(0.005)\end{array}$ & $\begin{array}{l}0.711 \\
(0.006)\end{array}$ & $\begin{array}{l}0.061 \\
(0.003)\end{array}$ \\
\hline Remember all & $\begin{array}{l}0.814 \\
(0.006)\end{array}$ & $\begin{array}{l}0.826 \\
(0.006)\end{array}$ & $\begin{array}{l}0.071 \\
(0.003)\end{array}$ & $\begin{array}{l}0.841 \\
(0.005)\end{array}$ & $\begin{array}{l}0.864 \\
(0.006)\end{array}$ & $\begin{array}{l}0.072 \\
(0.003)\end{array}$ & $\begin{array}{l}0.821 \\
(0.006)\end{array}$ & $\begin{array}{l}0.850 \\
(0.005)\end{array}$ & $\begin{array}{l}0.066 \\
(0.003)\end{array}$ \\
\hline
\end{tabular}

Numbers in parentheses are the standard error of the mean

\section{Discussion}

The forget-half condition of Experiment 1 revealed an overall directed forgetting effect, demonstrating the ability of participants to flexibly control the contents of memory even when studied items are complex photographic images (e.g., Hauswald \& Kissler, 2008). The magnitude of our directed forgetting effect (i.e., the difference in corrected hit rates for TBR and TBF items) did not differ as a function of negative (0.12), neutral (0.14), and positive (0.10) emotion. Notably, Quinlan et al. (2010) demonstrated that the magnitude of the directed forgetting tends to be smaller for pictures than for words: Whereas their presentation of concrete nouns at study produced a directed forgetting effect of 0.20 , this effect was reduced to 0.12 when simple coloured line drawings that depicted those nouns were studied instead. Our average directed forgetting effect of 0.12 was numerically identical to that obtained for line drawings in the Quinlan et al. (2010) study.

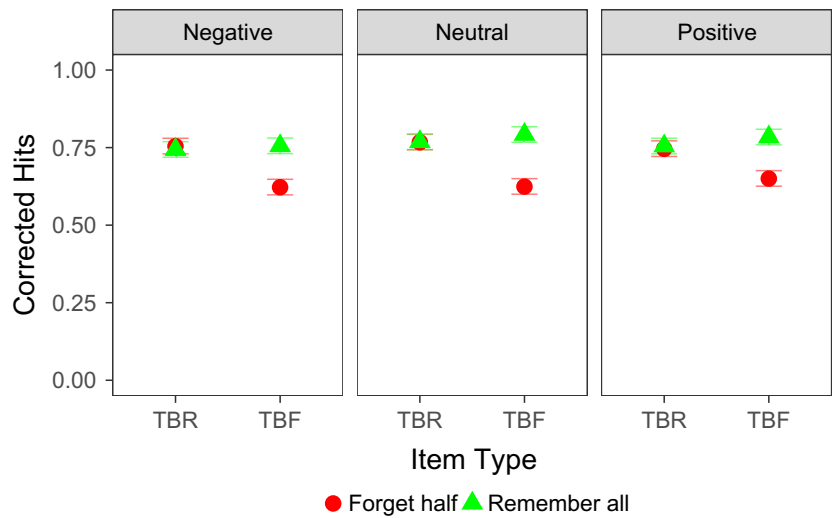

Fig. 1 Experiment 1. Corrected hit rates on the recognition test for each emotion (negative, neutral, positive) as a function of memory instruction (TBR, TBF) and condition (forget half, remember all). The TBR and TBF memory instructions for the remember-all condition were dummy coded and are interchangeable. Directed forgetting is revealed within the forgethalf condition (circles) by comparing performance for TBR and TBF items. Benefits are determined by comparing TBR item recognition for the forget-half (circles) and remember-all (triangles) conditions. Costs are determined by comparing TBF item recognition for the forget-half (circles) and remember-all (triangles) conditions. Error bars depict Fisher's least significant difference for the plotted effect. TBR $=$ to be remembered; $\mathrm{TBF}=$ to be forgotten
This suggests that the visual complexity of our pictures did not produce a smaller directed forgetting effect relative to simple line drawings. Even so, there might have been relatively little latitude for emotion to modulate the overall magnitude of the directed forgetting effect (apart perhaps from producing a null effect, which did not happen). Indeed, this is a potential limitation that applies to all manipulations aimed at influencing directed forgetting effects for pictorial stimuli (see Quinlan et al., 2010, for further discussion of this issue).

Regardless of potential differences (or lack thereof) in the magnitude of the directed forgetting effect for negative versus neutral pictures, our primary goal was to determine whether negative emotion influences the relative contributions of costs and benefits to the directed forgetting effects that are measured. On this our results were clear. Experiment 1 demonstrated that our recognition results were comprised entirely of costs without benefits (i.e., relatively impaired recognition of TBF items with no benefit for the recognition of TBR items). Interestingly, the pattern of costs without benefits was consistent across all three emotions: There was no compelling evidence that similar magnitude directed forgetting effects for negative, neutral, and positive pictures was due to different effects on underlying component processes.

Although our conclusion is that negative emotion therefore has no obvious impact on the directed forgetting effect or its underlying components, one might question this claim given that there was no memory enhancement for negative pictures in the remember-all control condition. We do not view the lack of memory enhancement as especially concerning, for reasons that we will explain in the General Discussion. Nevertheless, we acknowledge that seeking an effect of negative emotion on directed forgetting is predicated on the view that-compared to neutral pictures-negative pictures tend to be more easily remembered, and might therefore be less easily forgotten. Under this view, memory enhancement for negative items would seem to be a prerequisite for seeking effects of negative emotion on directed forgetting.

To determine whether our failure to observe memory enhancement for negative pictures was due to contamination of the remember-all condition by the forget-half condition, we repeated our analysis of remember-all performance but only using data 
from participants who completed this condition first. Restricting our analysis did not change the result: Even when it was completed first, there continued to be positive evidence against an effect of emotion on overall recognition accuracy in the remember-all condition, $p \mathrm{H} 0=0.87$. This compels the conclusion that when participants were instructed to commit all study items to memory, there was no evidence of better subsequent recognition of negative compared to neutral (and positive) pictures.

Given that Experiment 1 used a novel within-subjects design that required participants to complete both the forget-half and remember-all conditions, it seemed prudent to determine whether the same results would hold using a more typical between-subjects design. That was the goal of Experiment 2. Again, we were primarily interested in determining whether negative emotion impacts the costs and benefits of directed forgetting. But, as a prelude to this, we also assessed whether there was evidence for emotional enhancement when participants in a separate remember-all group were only ever required to commit all items to memory.

\section{Experiment 2}

Experiment 2 was conceptually identical to Experiment 1, except that different participants participated in forget-half and remember-all groups.

\section{Method}

\section{Participants}

A total of 60 students from Dalhousie University participated in the current study. They were assigned to one of the two groups: A forget-half group or a remember-all group. The intention was to run 30 participants in each group; however, an error led to data being collected from a total of 29 participants in the forgethalf group and 31 in the remember-all group. To balance the sample sizes, we excluded from all analyses those data collected from the last two participants in the remember-all group; this equated both groups to $n=29$. All participants were tested individually, in a single session lasting about 45 minutes, and received psychology course credit in exchange for their participation. All participants reported normal or corrected-to-normal vision and a good understanding of the English language.

\section{Stimuli and apparatus}

The stimuli and apparatus were as described for Experiment 1, except that the distribution of stimuli was changed to accommodate our use of a between-subjects design. Prior to collecting data from each participant, custom software was used to randomly subset the 96 negative, 96 neutral, and 96 positive pictures. A total of 24 negative, 24 neutral, and 24 positive pictures were designated as TBR items; 24 negative, 24 neutral, and 24 positive pictures were designated as TBF items; and 48 negative, 48 neutral, and 48 positive pictures were designated as unstudied foil items. In this way, every negative, neutral, and positive picture had equal opportunity to be presented as a TBR item, a TBF item, or a foil item, in both the forget-half and remember-all groups. We performed this randomisation anew before every participant to ensure unique stimulus combinations across our conditions.

\section{Procedure}

The procedure was as described for Experiment 1, with the following exceptions. Participants in the remember-all group were presented with the same high and low tones that were presented to the forget-half group, rather than only with a single high or low tone. The only difference is that these tones were given no associated memory instruction in the remember-all group; instead, these tones were described as "alerting tones" and participants were instructed to commit all pictures to memory. Just as the assignment of high and low tones to TBR and TBF items was counterbalanced across participants in the forget-half group, assignment of high and low tones to dummy coded "TBR" and "TBF" trials was counterbalanced across participants in the remember-all group. Thus, for half of the remember-all group, high-tone trials were dummy coded as TBR and low-tone trials were dummy coded as TBF; this mapping of tone to dummy code was reversed for the other half of participants in the remember-all group.

Familiarisation phase Familiarisation trials were as described for Experiment 1, except that no familiarisation trials were presented to the remember-all group, given that there was no tone-to-instruction mapping that they needed to learn.

Study phase There were a total of 144 study trials consisting of the random presentation of 48 negative, 48 neutral, and 48 positive pictures. Tone selection was determined by whether the randomly selected item was part of the TBR or TBF picture set and according to the counterbalancing of high and low tones to remember and forget instructions across participants. The stimulus and timing events were as described for Experiment 1.

Test phase Immediately following the presentation of all study phase trials, participants were presented with a yes-no recognition test. Instructions for this memory test appeared at the top of the computer monitor and remained visible throughout the duration of this phase. The test phase consisted of a total of 288 trials comprised of the random intermixing of the 48 negative, 48 neutral, and 48 positive pictures that had been presented at study and the 48 negative, 48 neutral, and 48 positive pictures that served as unstudied foils. The stimulus and timing events were as described for Experiment 1. 
Table 2 Experiment 2: Mean proportion hit rates to to-be-remembered (TBR) and to-be-forgotten (TBF) items and mean proportion false alarms to foil items, as a function of emotion (negative, neutral, positive) and group (forget half, remember all)

\begin{tabular}{|c|c|c|c|c|c|c|c|c|c|}
\hline & \multicolumn{3}{|l|}{ Negative } & \multicolumn{3}{|l|}{ Neutral } & \multicolumn{3}{|l|}{ Positive } \\
\hline & TBR & $\mathrm{TBF}$ & Foil & TBR & $\mathrm{TBF}$ & Foil & TBR & TBF & Foil \\
\hline Forget half & $\begin{array}{l}0.735 \\
(0.007)\end{array}$ & $\begin{array}{l}0.570 \\
(0.006)\end{array}$ & $\begin{array}{l}0.086 \\
(0.002)\end{array}$ & $\begin{array}{l}0.757 \\
(0.007)\end{array}$ & $\begin{array}{l}0.568 \\
(0.007)\end{array}$ & $\begin{array}{l}0.082 \\
(0.002)\end{array}$ & $\begin{array}{l}0.721 \\
(0.006)\end{array}$ & $\begin{array}{l}0.568 \\
(0.006)\end{array}$ & $\begin{array}{l}0.033 \\
(0.002)\end{array}$ \\
\hline Remember all & $\begin{array}{l}0.788 \\
(0.005)\end{array}$ & $\begin{array}{l}0.757 \\
(0.004)\end{array}$ & $0.111(0.005)$ & $\begin{array}{l}0.722 \\
(0.006)\end{array}$ & $\begin{array}{l}0.732 \\
(0.006)\end{array}$ & $\begin{array}{l}0.110 \\
(0.005)\end{array}$ & $\begin{array}{l}0.719 \\
(0.005)\end{array}$ & $\begin{array}{l}0.756 \\
(0.004)\end{array}$ & $\begin{array}{l}0.058 \\
(0.004)\end{array}$ \\
\hline
\end{tabular}

Numbers in parentheses are the standard error of the mean

Data analysis Data were analysed as described for Experiment 1.

\section{Results}

A hit was defined as a yes response to TBR and TBF items (actual or dummy- coded); a false alarm was defined as a yes response to unstudied foil items. The mean proportion hit and false alarm rates for each group are shown in Table 2 as a function of memory instruction and emotion. To provide a measure of recognition accuracy corrected for guessing, we subtracted on a subject-by-subject basis the mean proportion false alarms from the mean proportion TBR and TBF hits, separately for each emotion (negative, neutral, positive). ${ }^{4}$ The mean corrected hit rates are shown in Fig. 2.

Before proceeding to our primary analyses, we first analysed corrected hit rates in the remember-all control group, as a function of emotion (negative, neutral, positive). This analysis revealed strong evidence for an effect of emotion, $p \mathrm{H} 1=0.96$, with overall higher memory accuracy in the remember-all group for negative $(M=0.66)$ and positive ( $M$ $=0.68)$ pictures than for neutral pictures $(M=0.62)$. Thus, in contrast to Experiment 1, the results of Experiment 2 revealed emotional memory enhancement in the remember-all control group.

We then analysed the corrected hit rates in the forget-half group, as a function of memory instruction (TBR, TBF) and emotion (negative, neutral, positive). This analysis provided very strong evidence for an effect of memory instruction, $p \mathrm{H} 1$ $>0.99$, consistent with an overall directed forgetting effect (i.e., better memory for TBR than TBF items). However, there was weak evidence against a main effect of emotion, $p \mathrm{HO}=$ 0.70 , and strong evidence against an interaction of memory instruction and emotion, $p \mathrm{HO}=0.97$. In other words, there was a robust directed forgetting effect in the forget-half

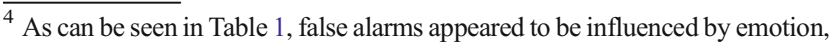
with overall fewer false alarms made to positive pictures than to either negative or neutral pictures. Indeed, an analysis of false alarms as a function of group and emotion provided positive evidence against an effect of group, $p \mathrm{H} 0=$ 0.83 , but very strong support for an effect of emotion, $p \mathrm{H} 1>0.99$, and very strong evidence against an interaction of group and emotion, $p \mathrm{H} 0>0.99$.
}

condition (i.e., better recognition of TBR than TBF items), the magnitude of which was not influenced by emotion.

To examine the costs to memory of instructing participants to forget half of the items they were later asked to recognise, we analysed corrected hit rates for TBF items (actual or dummy coded), as a function of group (forget half, remember all) and emotion (negative, neutral, positive). Our data provided positive evidence for a difference in recognition accuracy, with greater recognition when these items were dummycoded trials from the remember-all group, compared to when they were trials that participants were actually instructed to forget in the forget-half group, $p \mathrm{H} 1=0.93$. There was also positive evidence for an effect of emotion on TBF item recognition, $p \mathrm{H} 1=0.90$ : Collapsed across the remember-all and forget-half groups, recognition accuracy for TBF items was overall higher for positive items $(M=0.61)$ compared to negative $(M=0.57)$ and neutral $(M=0.58)$ items. Critically, for present purposes, there was strong evidence against an

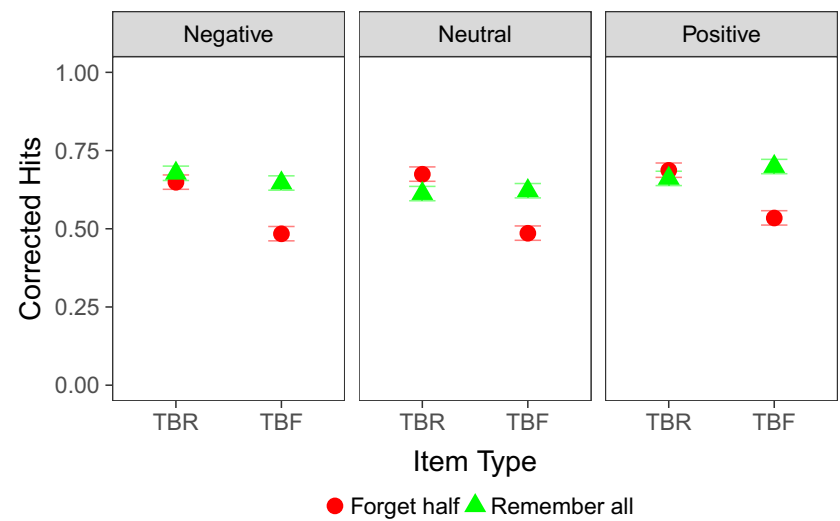

Fig. 2 Experiment 2. Corrected hit rates on the recognition test for each emotion (negative, neutral, positive) as a function of memory instruction (TBR, TBF) and group (forget half, remember all). The TBR and TBF memory instructions for the remember-all group were dummy coded and are interchangeable. Directed forgetting is revealed within the forget-half group (circles) by comparing performance for TBR and TBF items. Benefits are determined by comparing TBR item recognition for the forget-half (circles) and remember-all (triangles) groups. Costs are determined by comparing TBF item recognition for the forget-half (circles) and remember-all (triangles) groups. Error bars depict Fisher's least significant difference for the plotted effect. $\mathrm{TBR}=$ to be remembered; $\mathrm{TBF}=$ to be forgotten 
interaction of group and emotion, $p \mathrm{H} 0=0.99$. In other words, there were costs to memory of being instructed to forget items that participants were later asked to recognise (i.e., TBF items showed overall lower recognition in the forget-half group than in the remember-all group), but these costs did not vary by emotion.

To examine benefits to memory of allowing participants to forget half of the study items, we analysed corrected hit rates for TBR items (actual or dummy coded) as a function of group (forget half and remember all) and emotion (negative, neutral, positive). This analysis revealed positive evidence against an effect of group, $p \mathrm{HO}=0.88$. This argues against overall benefits in recognition for the forget-half group compared to the remember-all group: TBR item recognition did not benefit from participants being required to commit only half-rather than all —of the study items to memory. There was also positive evidence against an effect of emotion on TBR item recognition, $p \mathrm{HO}=0.94$, and weak evidence against an interaction of group with emotion, $p \mathrm{H} 0=0.65$. In other words, across the three emotions, being allowed to forget half of the studied items conferred no compelling evidence of benefits to subsequent memory for the TBR items.

\section{Discussion}

Similar to the findings of Experiment 1, performance in the forget-half group of Experiment 2 revealed an overall directed forgetting effect for complex photographic images. The magnitude of this directed forgetting effect (i.e., the difference in corrected hit rates for TBR vs. TBF pictures) was 0.16 for negative pictures, 0.19 for neutral pictures, and 0.15 for positive pictures, for an average of 0.17 . To understand how these values compared to Experiment 1, we calculated the directed forgetting effect on a subject-by-subject basis in the forgethalf condition of Experiment 1 and in the forget-half group of Experiment 2. These directed forgetting effects were then analysed with experiment as a between-subjects factor and emotion as a within-subjects factor (negative, neutral, positive). There was weak evidence against a main effect of Experiment, $p \mathrm{H} 0=0.74$, strong evidence against an effect of emotion, $p \mathrm{HO}=0.97$, and very strong evidence against an interaction of experiment and emotion, $p \mathrm{H} 0>0.99$. In other words, Experiment 1 and Experiment 2 produced similar magnitude directed forgetting effects, with no evidence of modulation by emotion.

As was true for Experiment 1, the directed forgetting effect in recognition was comprised entirely of costs without benefits (i.e., relatively impaired recognition of TBF items with no benefit in the recognition of TBR items). Again, the pattern of costs without benefits held across all three emotions: There was no evidence of different component processes underlying the directed forgetting effects for negative, neutral, and positive pictures.
Unlike in Experiment 1, when participants in Experiment 2 only ever had to commit all items to memory (i.e., the remember-all group), they showed greater recognition of both negative and positive pictures compared to neutral pictures. Despite this emotional enhancement effect in Experiment 2 but not in Experiment 1, the overall pattern of results with respect to the effects of emotion on the costs and benefits of directed forgetting was the same in both experiments.

\section{General discussion}

Typically, directed forgetting effects are measured as a relative difference in subsequent memory performance for TBR and TBF items, without distinguishing the contributions of costs (decreased memory for TBF items) from benefits (increased memory for TBR items). Because the directed forgetting effect measures costs plus benefits, any changes in the magnitude of this effect can be due to changes in either or both components (e.g., MacLeod, 1998; see Sahakyan \& Foster, 2009). For this reason, we elected to examine directed forgetting effects for negative, neutral, and positive complex photographic pictures by including a within-subjects remember-all control condition in Experiment 1 and a separate remember-all control group in Experiment 2. Our data provided evidence of costs without benefits in both experiments-attesting to the fact that the directed forgetting effect was, in fact, due to processes related to instantiating the intention to forget (i.e., the directed forgetting effects were due to worse TBF item performance when participants were instructed to forget these items, compared to when they were required to remember all study items). Importantly, these costs without benefits occurred across all three emotions, with no evidence that negative emotion limits the intentional forgetting of unwanted items. While benefits in an item-method task may be obtained using measures of recall (e.g., Sahakyan \& Foster, 2009), our experience suggests that they tend to be small and not very robust for measures of recognition within an item-method paradigm (see also Taylor \& Fawcett, 2012). The current pattern of costs without benefits is therefore not without precedent.

Although we think it unlikely, it is possible that the absence of significant benefits - particularly in Experiment 2-could be due to the different tasks demands in the forget-half and remember-all groups. Whereas participants in the rememberall group had to simply attend to each picture and try to commit it to memory without reference to the tone identity, participants in the forget-half group were required to map the tone (high or low frequency) onto the corresponding memory intention. We did try to facilitate the tone mapping by providing tone familiarisation trials to the forget-half group before proceeding with the experiment. Nevertheless, any benefit of having to remember only half of the pictures in the forget- 
half group could conceivably have been reduced or masked by the additional task demand of having to interpret the tone and enact the memory instruction. That said, the fact that we also observed a pattern of costs without benefits in Experiment 1 makes this argument less tenable. This is because a consistent tone-to-instruction mapping was used across both the forgethalf and remember-all conditions - the only factor that differed across blocks was whether the remember tone was repeated on only half the trials or on all of the trials. Moreover, if relative difficulty of the forget-half tone mapping were responsible for reducing benefits, one might expect smaller benefits when the forget-half block was completed first rather than second (i.e., because when completed second, participants will have gained repeated exposure to the remember tone in the preceding Remember-all condition, thus making the tone mapping easier than if they had to complete the forget-half condition first). To address this possibility, we separated our Experiment 1 data according to block order (i.e., forget half/remember all, remember all/forget half) and then subtracted average corrected hit rates for TBR items in the forget-half condition from corrected hit rates for dummycoded TBR items in the remember-all condition. This subtraction revealed benefits that were numerically larger for participants who completed the forget-half condition first $(M=$ 0.05 ), than for participants who completed the forget-half condition second $(M=-0.05)$. We are thus inclined to believe that there were, in fact, costs without benefits across all three emotions and that this was not due to relative difficulty in performing the tone-to-instruction mapping on the forgethalf trials. In short, the equivalent directed forgetting effects obtained across all three emotions was due to similar underlying processes, related to the successful instantiation of the forget instruction.

As we have already noted, there was no consistent effect of emotion on recognition accuracy when participants were required to remember all pictures: In the remember-all control condition of Experiment 1, there was evidence against an effect of emotion; in the remember-all control group of Experiment 2, recognition accuracy was higher for both negative and positive pictures compared to neutral pictures. We understand that an expectation of emotionenhanced memory has driven much of the interest in understanding the effects of emotion on directed forgetting. However, a strong expectation of consistent emotionenhanced memory might be misguided. Dougal and Rotello (2007) argue that a response bias is more likely to explain emotion-enhanced memory for recognition than changes in item discriminability. Although their conclusion is based on a study of emotional word recognition, it suggests skepticism in expecting a robust effect of emotion on remember-all picture recognition in the present study.
Moreover, even when emotional enhancement does occur, it may reflect processes that enhance memory consolidation (see LaBar \& Cabeza, 2006; Talmi, 2013) over longer intervals than tested here (e.g., Buchanan \& Lovallo, 2001; Dolcos, LaBar, \& Cabeza, 2005; Kleinsmith \& Kaplan, 1963; LaBar \& Phelps, 1998; Sharot \& Phelps, 2004). Consolidation processes that unfold over time would not necessarily impact control over initial encoding and be detectable at the relatively short retention intervals that we tested. Nevertheless, it would seem worthwhile for future investigations to determine whether these consolidation processes interact with the quality of encoded information to magnify differences in directed forgetting effects that are measured for negative, neutral, and positive pictures after retention intervals of hours or days. In any case, the present findings are clear that - at least over the retention intervals that we tested - there seems to be no contingent relationship between emotional memory enhancement on the one hand and intentional forgetting on the other. Despite emotion-enhanced memory in the remember-all group of Experiment 2 but not in the remember-all condition of Experiment 1, both experiments provided evidence against an effect of emotion on directed forgetting. This suggests that even when emotional pictures are more likely to be remembered, they are not less likely to be forgotten.

Equivalent directed forgetting effects across negative, neutral, and positive pictures accords with other findings from our lab, which showed equivalent directed forgetting effects for human faces displaying angry, neutral, and happy expressions (Quinlan \& Taylor, 2014). Taken together, these results underscore the considerable flexibility that participants have in exerting cognitive control over encoding and highlight their ability to limit unwanted encoding of complex picture as well as human face stimuli, regardless of emotional content or expression. That said, our finding of directed forgetting effects for all levels of emotion contrasts with others who have reported a failure to find a significant directed forgetting effect for negative pictures despite a significant directed forgetting effect for neutral pictures (e.g., Hauswald et al., 2010). However, this failure to find a directed forgetting effect for negative pictures that are intermixed at study with neutral pictures might not necessarily defy our conclusion that negative pictures can, in fact, be intentionally forgotten at the same rate as neutral (and positive) pictures. It seems possible that in the context of a block of trials that otherwise presents only neutral pictures, arousing negative pictures become relatively distinctive (e.g., Dewhurst \& Parry, 2000; Talmi, Luk, McGarry, \& Moscovitch, 2007). High distinctiveness can override intentions to forget at encoding (e.g., Hourihan \& MacLeod, 2008; MacLeod \& Daniels, 2000). 
Similarly, salient and unusual items tend to attract attention and receive preferential processing (see Matthews \& Meck, 2016), which could hinder the withdrawal of attention from TBF negative pictures. By intermixing positively arousing pictures with neutral and negatively arousing pictures in our attempt to separate potential valence effects from arousal effects, we also likely reduced the salience and relative distinctiveness of the negative items (although see, for example, Gallant \& Dyson, 2016, for intermixing of words that led to different magnitude directed forgetting effects). In so doing, we determined that control over encoding can, in fact, be successfully applied to negative photographic images - at least when they are intermixed with neutral and relatively arousing positive items. By decomposing our results into costs and benefits, we further demonstrated that these directed forgetting effects are due specifically to costs that are incurred as a result of successfully enacting the intention to forget, rather than to benefits that derive from the redirection of processing resources to the remaining TBR items.

With that being said, this interpretation of our results is not without an important caveat. We were primarily interested in determining whether the parcelling of directed forgetting effects into costs and benefits would differ for negative and neutral pictures. We included positive pictures in an attempt to provide some control for different arousal levels between negative and neutral pictures. But this control was not perfect. Our negative pictures were more arousing than our positive pictures. On the one hand, the fact of similar magnitude costs without benefits across all three levels of emotion - negative, neutral, and positive - argues that differences in neither valence nor arousal affected the component processes of the itemmethod directed forgetting effect. On the other hand, even our negative pictures had an average arousal rating of only 5.26 on a 1-point to 9-point scale, on which 9 is maximally arousing. We were primarily focused on a comparison of negative to neutral pictures and so endeavoured to select pictures that were as negative as ethical considerations would allow. Especially to the extent that arousal plays a role in decreasing the directed forgetting effect for negative pictures (e.g., Hauswald et al., 2010), there is always the possibility that the directed forgetting effect and its underlying components could be influenced by more extreme manipulations of arousal than we employed. Even so, we would argue that for the types of nonextreme positively and negatively arousing images that people might expect to encounter in their everyday lives-for example, through entertainment or news media - there is a remarkable ability to exert control over the contents of encoding. It remains to be determined whether this is also the case for more extreme, shocking, gory, graphic, horrifying, sexually explicit, or personally relevant emotional images.
This caveat notwithstanding, the notion that directed forgetting effects for negative, neutral, and positive pictures are attributable to successful instantiation of the forget instruction is an intriguing result in light of findings reported by Yang et al. (2012). Using a paradigm very similar to ours, Yang et al. (2012) measured event-related potentials (ERP) during an item-method paradigm that presented arousal-matched negative and neutral pictures. In the first 200-300 ms following a forget instruction there was a larger negative deflection over frontal sites for negative than for neutral pictures. Linking this deflection to the N2 component, they argued that instantiating a forget instruction requires more effort for negative than for neutral pictures (see also Nowicka et al., 2010). This was true despite no significant interaction of emotion and memory instruction in the analysis of subsequent recognition hit rates. Together with our findings, this suggests that even when an intention to forget leads to equivalent performance across negative, neutral, and positive pictures there may nevertheless be differences in the underlying effort needed to achieve equivalent performance. This seems a fruitful avenue for future investigation.

\section{Conclusion}

Regardless of whether additional effort must be exerted to successfully forget negative compared to neutral (and/or positive) pictures, our results suggest that the end result in terms of behavioural outcome is the same: Directed forgetting effects occur to the same extent whether participants are asked to exert control over the encoding of complex negative, neutral, or positive pictures. By separating directed forgetting effects into costs and benefits, we determined that the itemmethod directed forgetting effect in recognition is due entirely to decreased subsequent recognition of TBF items (costs), rather than increased recognition of TBR items (benefits). The fact that costs did not differ as a function of emotion argues that underlying cognitive mechanisms are equally effective at intentionally forgetting unwanted negative, neutral, and positive pictures

Authors' note Thanks to Carl Helmick for providing the custom software used to randomise and distribute the picture stimuli, to Laura Cutmore for collecting the data for Experiment 1, and to our participants for volunteering their time and effort to contribute data toward this project. Data for Experiment 2 were collected by K.C.H.V. as part of a thirdyear undergraduate research course completed at Dalhousie University during an exchange with the University of Maastricht; this research course was cosupervised by C.K.Q. and T.L.T. Doctoral scholarship support was provided to 
C.K.Q. from the Killam foundation and from the Natural Sciences and Engineering Research Council (NSERC) of Canada. Project funding was provided by an NSERC Discovery Grant awarded to T.L.T.

\section{Appendix A}

Table 3 Pictures drawn from the IAPS database, referenced by number

\begin{tabular}{llllllll}
\hline Negative & & & & & & & \\
1111 & 2312 & 2703 & 3230 & 6312 & 9041 & 9280 & 9560 \\
1220 & 2399 & 2718 & 3280 & 6370 & 9046 & 9290 & 9561 \\
1274 & 2455 & 2745.2 & 3300 & 6561 & 9050 & 9331 & 9600 \\
1280 & 2490 & 2751 & 3500 & 6821 & 9090 & 9342 & 9611 \\
1525 & 2590 & 2753 & 4621 & 6830 & 9110 & 9415 & 9622 \\
1930 & 2661 & 2799 & 5971 & 6940 & 9120 & 9419 & 9800 \\
2095 & 2682 & 2800 & 6010 & 7361 & 9140 & 9430 & 9810 \\
2120 & 2683 & 2811 & 6020 & 7380 & 9160 & 9432 & 9830 \\
2141 & 2688 & 2900.1 & 6210 & 8485 & 9180 & 9435 & 9910 \\
2205 & 2691 & 3022 & 6213 & 9000 & 9182 & 9440 & 9912 \\
2276 & 2692 & 3180 & 6300 & 9010 & 9250 & 9470 & 9925 \\
2278 & 2700 & 3216 & 6311 & 9040 & 9270 & 9520 & 9926 \\
Neutral & & & & & & & \\
1935 & 2575 & 2980 & 7004 & 7043 & 7090 & 7190 & 7506 \\
1945 & 2579 & 5120 & 7006 & 7044 & 7100 & 7192 & 7547 \\
2200 & 2595 & 5130 & 7009 & 7050 & 7130 & 7205 & 7550 \\
2215 & 2635 & 5395 & 7010 & 7052 & 7140 & 7207 & 7595 \\
2221 & 2702 & 5471 & 7020 & 7053 & 7150 & 7217 & 7705 \\
2280 & 2704 & 5510 & 7025 & 7055 & 7160 & 7224 & 7710 \\
2381 & 2745.1 & 5535 & 7030 & 7056 & 7161 & 7233 & 7830 \\
2410 & 2749 & 5740 & 7031 & 7057 & 7175 & 7234 & 7950 \\
2441 & 2780 & 6150 & 7034 & 7058 & 7179 & 7235 & 9401 \\
2446 & 2840 & 6570.2 & 7036 & 7059 & 7180 & 7242 & 9635.2 \\
2487 & 2880 & 7000 & 7037 & 7060 & 7183 & 7487 & 9700 \\
2516 & 2890 & 7002 & 7040 & 7080 & 7187 & 7490 & 9913 \\
Positive & & & & & & \\
1333 & 1670 & 2030 & 2370 & 4542 & 5600 & 5890 & 7502 \\
1340 & 1710 & 2050 & 2373 & 4599 & 5621 & 5994 & 7545 \\
1419 & 1721 & 2091 & 2389 & 4614 & 5623 & 7200 & 7580 \\
1441 & 1750 & 2092 & 2398 & 4626 & 5629 & 7220 & 8030 \\
1450 & 1810 & 2153 & 2442 & 5200 & 5635 & 7230 & 8033 \\
1460 & 1811 & 2154 & 2510 & 5260 & 5779 & 7250 & 8162 \\
1500 & 1812 & 2165 & 2515 & 5300 & 5781 & 7270 & 8370 \\
1600 & 1900 & 2209 & 2530 & 5410 & 5800 & 7280 & 8490 \\
1601 & 1920 & 2216 & 2560 & 5450 & 5830 & 7286 & 8497 \\
1604 & 1942 & 2331 & 2605 & 5470 & 5831 & 7325 & 8500 \\
\hline & 1999 & 2352 & 2791 & 5480 & 5833 & 7350 & 8501 \\
1620 & 2362 & 4535 & 5594 & 5875 & 7430 & 8510 \\
\hline
\end{tabular}

\section{References}

Anderson, M. C., \& Hanslmayr, S. (2014). Neural mechanisms of motivated forgetting. Trends in Cognitive Sciences, 18(6), 279-92.

Bailey, K., \& Chapman, P. (2012). When can we choose to forget? An ERP study into item-method directed forgetting of emotional words. Brain and Cognition, 78(2), 133-147.

Basden, B. H., Basden, D. R., \& Gargano, G. J. (1993). Directed forgetting in implicit and explicit memory tests: A comparison of methods. Journal of Experimental Psychology: Learning, Memory, and Cognition, 19, 603-616.

Bastin, C., Feyers, D., Majerus, S., Balteau, E., Degueldre, C., Luxen, A., . . Collette, F. (2012). The neural substrates of memory suppression: A FMRI exploration of directed forgetting. PLOS ONE, 7(1), e29905.

Bjork, R. A. (1972). Theoretical implications of directed forgetting. In A. W. Melton \& E. Martin (Eds.), Coding processes in human memory (pp. 217-235). Washington, DC: Winston.

Bjork, R. A., Bjork, E. L., \& Anderson, M. C. (1998). Varieties of goaldirected forgetting. In J. M. Golding \& C. M. MacLeod (Eds.), Intentional forgetting: Interdisciplinary approaches (pp. 103-137). Mahwah, NJ: Erlbaum.

Brandt, K. R., Nielsen, M. K., \& Holmes, A. (2013). Forgetting emotional and neutral words: An ERP study. Brain Research, 1501, 21-31.

Buchanan, T. W., \& Lovallo, W. R. (2001). Enhanced memory for emotional material following stress-level cortisol treatment in humans. Psychoneuroendocrinology, 26(3), 307-317.

Cheng, S., Liu, I., Lee, J. R., Hung D. L., \& Tzeng, O. J.-L. (2012). Intention forgetting might be more effortful than remembering: An ERP study of item-method directed forgetting. Biological Psychology, 89, 283-292.

Cloitre, M., Cancienne, J., Brodsky, B., Dulit, R., \& Perry, S. W. (1996). Memory performance among women with parental abuse histories: Enhanced directed forgetting or directed remembering?. Journal of Abnormal Psychology, 105(2), 204-211.

Cohen, J. D., MacWhinney, B., Flatt, M., \& Provost, J. (1993). PsyScope: An interactive graphic system for designing and controlling experiments in the psychology laboratory using Macintosh computers. Behavior Research Methods, Instruments, \& Computers, 25, 257271.

Dewhurst, S. A., \& Parry, L. A. (2000). Emotionality, distinctiveness, and recollective experience. European Journal of Cognitive Psychology, 12(4), 541-551.

Dolcos, F., \& Cabeza, R. (2002). Event-related potentials of emotional memory: Encoding pleasant, unpleasant, and neutral pictures. Cognitive, Affective, \& Behavioral Neuroscience, 2(3), 252-263.

Dolcos, F., LaBar, K. S., \& Cabeza, R. (2005). Remembering one year later: role of the amygdala and the medial temporal lobe memory system in retrieving emotional memories. Proceedings of the National Academy of Sciences of the United States of America, 102(7), 2626-2631.

Dougal, S., \& Rotello, C. M. (2007). "Remembering" emotional words is based on response bias, not recollection. Psychonomic Bulletin \& Review, 14(3), 423-429.

Elzinga, B. M., de Beurs, E., Sergeant, J. A., Van Dyck, R., \& Phaf, R. H. (2000). Dissociative style and directed forgetting. Cognitive Therapy and Research, 24(3), 279-295.

Elzinga, B. M., Phaf, R. H., Ardon, A. M., \& van Dyck, R. (2003). Directed forgetting between, but not within, dissociative personality states. Journal of Abnormal Psychology, 112(2), 237-243.

Fawcett, J. M., Lawrence, M. A., \& Taylor, T. L. (2016). The representational consequences of intentional forgetting: Impairments to both the probability and fidelity of long-term memory. Journal of Experimental Psychology: General, 145(1), 56-81. 
Fawcett, J. M., \& Taylor, T. L. (2008). Forgetting is effortful: Evidence from reaction time probes in an item-method directed forgetting task. Memory \& Cognition, 6, 1168-1181.

Fawcett, J. M., \& Taylor, T. L. (2010). Directed forgetting shares mechanisms with attentional withdrawal but not with stop-signal inhibition. Memory \& Cognition, 38, 797-808.

Fawcett, J. M., \& Taylor, T. L. (2012). The control of working memory resources in intentional forgetting: Evidence from incidental probe word recognition. Acta Psychologica, 139, 84-90.

Gallant, S. N., \& Dyson, B. J. (2016). Neural modulation of directed forgetting by valence and arousal: An event-related potential study. Brain Research, 1648, 306-316.

Gallant, S. N., \& Yang, L. (2014). Positivity effect in source attributions of arousal-matched emotional and non-emotional words during item-based directed forgetting. Frontiers in Psychology, 5, 1334.

Gardiner, J. M., Gawlik, B., \& Richardson-Klavehn, A. (1994). Maintenance rehearsal affects knowing, not remembering: Elaborative rehearsal affects remembering, not knowing. Psychonomic Bulletin \& Review, 1(1), 107-110.

Geiselman, R. E., Bjork, R. A., \& Fishman, D. L. (1983). Disrupted retrieval in directed forgetting: A link with posthypnotic amnesia. Journal of Experimental Psychology: General, 112(1), 58.

Goernert, P. N., Corenblum, B., \& Otani, H. (2011). Directed forgetting of faces: The role of response criterion. The Quarterly Journal of Experimental Psychology, 64(10), 1930-1938.

Gottlob, L. R., Golding, J. M., \& Hauselt, W. J. (2006). Directed forgetting of a single item. The Journal of General Psychology, 133(1), 67-80.

Hamann, S. B., Ely, T. D., Grafton, S. T., \& Kilts, C. D. (1999). Amygdala activity related to enhanced memory for pleasant and aversive stimuli. Nature Neuroscience, 2(3), 289-293.

Hauswald, A., \& Kissler, J. (2008). Directed forgetting of complex pictures in an item method paradigm. Memory, 16(8), 797-809.

Hauswald, A., Schulz, H., Iordanov, T., \& Kissler, J. (2010). ERP dynamics underlying successful directed forgetting of neutral but not negative pictures. Social Cognitive and Affective Neuroscience, 6(4), 450-459.

Hourihan, K. L., \& MacLeod, C. M. (2008). Directed forgetting meets the production effect: Distinctive processing is resistant to intentional forgetting. Canadian Journal of Experimental Psychology, 62(4), 242-246.

Hourihan, K. L., Ozubko, J. D., \& MacLeod, C. M. (2009). Directed forgetting of visual symbols: Evidence for nonverbal selective rehearsal. Memory \& Cognition, 37(8), 1059-1068.

Hourihan, K. L., \& Taylor, T. L. (2006). Cease remembering: Executive control processes in directed forgetting. Journal of Experimental Psychology: Human Perception \& Performance, 32, 1354-1365.

Hsieh, L. T., Hung, D. L., Tzeng, O. J. L., Lee, J. R., \& Cheng, S. K. (2009). An event-related potential investigation of the processing of remember/forget cues and item encoding in item-method directed forgetting. Brain Research, 1250, 190-201.

Jonides, J., \& Mack, R. (1984). On the cost and benefit of cost and benefit. Psychological Bulletin, 96, 29-44.

Kanwisher, N., McDermott, J., \& Chun, M. M. (1997). The fusiform face area: A module in human extrastriate cortex specialized for face perception. Journal of Neuroscience, 17(11), 4302-4311.

Kensinger, E. A., \& Corkin, S. (2003). Memory enhancement for emotional words: Are emotional words more vividly remembered than neutral words? Memory \& Cognition, 31(8), 1169-1180.

Kleinsmith, L. J., \& Kaplan, S. (1963). Paired-associate learning as a function of arousal and interpolated interval. Journal of Experimental Psychology, 65, 190-193.

Korfine, L., \& Hooley, J. M. (2000). Directed forgetting of emotional stimuli in borderline personality disorder. Journal of Abnormal Psychology, 109(2), 214-221.
Kruschke, J. K., \& Liddell, T. M. (2017). The Bayesian new statistics: Hypothesis testing, estimation, meta-analysis, and power analysis from a Bayesian perspective. Psychonomic Bulletin \& Review, 129. doi:https://doi.org/10.3758/s13423-016-1221-4

LaBar, K. S., \& Cabeza, R. (2006). Cognitive neuroscience of emotional memory. Nature Reviews Neuroscience, 7(1), 54-64.

LaBar, K. S., \& Phelps, E. A. (1998). Arousal-mediated memory consolidation: Role of the medial temporal lobe in humans. Psychological Science, 9, 527-540.

Lang, P. J., Bradley, M. M., \& Cuthbert, B. N. (2005). International affective picture system (IAPS): Affective ratings of pictures and instruction manual (Technical Report A-6, pp. 1-6). Gainesville, FL: University of Florida.

Lawrence, M. A. (2016). ez: Easy analysis and visualization of factorial experiment (Package Version 4.4-0) [Computer software]. Retrieved from https://CRAN.R-project.org/package=ez

Liang, C. W., Hsu, W. Y., Hung, F. C., Wang, W. T., \& Lin, C. H. (2011). Absence of a positive bias in social anxiety: The application of a directed forgetting paradigm. Journal of Behavior Therapy and Experimental Psychiatry, 42(2), 204-210.

MacLeod, C. M. (1998). Directed forgetting. In J. M. Golding \& C. M. MacLeod (Eds.), Intentional forgetting: Interdisciplinary approaches (pp. 1-57). Mahwah, NJ: Erlbaum.

MacLeod, C. M., \& Daniels, K. A. (2000). Direct versus indirect tests of memory: Directed forgetting meets the generation effect. Psychonomic Bulletin \& Review, 7(2), 354-359.

Masson, M. E. (2011). A tutorial on a practical Bayesian alternative to null-hypothesis significance testing. Behavior Research Methods, 43(3), 679-690.

Matthews, W. J., \& Meck, W. H. (2016). Temporal cognition: Connecting subjective time to perception, attention, and memory. Psychological Bulletin, 142(8), 865-907.

McNally, R. J., Clancy, S. A., \& Schacter, D. L. (2001). Directed forgetting of trauma cues in adults reporting repressed or recovered memories of childhood sexual abuse. Journal of Abnormal Psychology, 110(1), 151-156.

McNally, R. J., Metzger, L. J., Lasko, N. B., Clancy, S. A., \& Pitman, R. K. (1998). Directed forgetting of trauma cues in adult survivors of childhood sexual abuse with and without posttraumatic stress disorder. Journal of Abnormal Psychology, 107, 596-601.

McNally, R. J., Otto, M. W., Yap, L., Pollack, M. H., \& Hornig, C. D. (1999). Is panic disorder linked to cognitive avoidance of threatening information? Journal of Anxiety Disorders, 13, 335-348.

Moulds, M. L., \& Bryant, R. A. (2002). Directed forgetting in acute stress disorder. Journal of Abnormal Psychology, 111, 175-179.

Nowicka, A., Marchewka, A., Jednorog, K, Tacikowski, P., \& Brechmann, A. (2010). Forgetting of emotional information is hard: An fMRI study of directed forgetting. Cerebral Cortex, 21, 539-549.

Ochsner, K. N. (2000). Are affective events richly recollected or simply familiar? The experience and process of recognizing feelings past. Journal of Experimental Psychology: General, 129, 242-261.

Otani, H., Libkuman, T. M., Goernert, P. N., Kato, K., Migita, M., Freehafer, S. E., \& Landow, M. P. (2012). Emotion, directed forgetting, and source memory. British Journal of Psychology, 103(3), $343-358$.

Paller, K. A. (1990). Recall and stem-completion priming have different electrophysiological correlates and are modified differentially by directed forgetting. Journal of Experimental Psychology: Learning, Memory, and Cognition, 16, 1021-1032.

Patrick, R. E., Kiang, M., \& Christensen, B. K. (2015). Neurophysiological correlates of emotional directed-forgetting in persons with Schizophrenia: An event-related brain potential study. International Journal of Psychophysiology, 98, 612-623.

Paz-Caballero, M. D., Menor, J., \& Jiménez, J. M. (2004). Predictive validity of event-related potentials (ERPs) in relation to the directed forgetting effects. Clinical Neurophysiology, 115, 369-377. 
Quinlan, C. K., \& Taylor, T. L. (2014). "I never forget a face, but in your case I'll be glad to make an exception": Intention forgetting of emotional faces. Canadian Journal of Experimental Psychology, $68,212-221$.

Quinlan, C. K., Taylor, T. L., \& Fawcett, J. M. (2010). Directed forgetting: Comparing pictures and words. Canadian Journal of Experimental Psychology, 64, 41-46.

R Core Team. (2017). R: A language and environment for statistical computing. Vienna, Austria: R Foundation for Statistical Computing. Retrieved from http://www.R-project.org/

Raftery, A. E. (1995). Bayesian model selection in social research. Sociological Methodology, 25, 111-164.

Rizio, A. A., \& Dennis, N. A. (2013). The neural correlates of cognitive control: Successful remembering and intentional forgetting. Journal of Cognitive Neuroscience, 25, 297-312.

Sahakyan, L., \& Foster, N. L. (2009). Intentional forgetting of actions: Comparison of list-method and item-method directed forgetting. Journal of Memory and Language, 61, 134-152.

Sahakyan, L., \& Kelley, C. M. (2002). A contextual change account of the directed forgetting effect. Journal of Experimental Psychology: Learning, Memory, and Cognition, 28, 1064-1072.

Sharot, T., \& Phelps, E. A. (2004). How arousal modulates memory: disentangling the effects of attention and retention. Cognitive, Affective, \& Behavioral Neuroscience, 4, 294-306.

Talmi, D. (2013). Enhanced emotional memory: Cognitive and neural mechanisms. Current Directions in Psychological Science, 22, 430-436.

Talmi, D., Luk, B. T., McGarry, L. M., \& Moscovitch, M. (2007). The contribution of relatedness and distinctiveness to emotionallyenhanced memory. Journal of Memory and Language, 56, 555-574.

Taylor, T. L. (2005). Inhibition of return following instructions to remember and forget. The Quarterly Journal of Experimental Psychology, 58A, 613-629 (Erratum in 58A, 1343).

Taylor, T. L., \& Fawcett, J. M. (2011). Larger IOR effects following forget than following remember instructions depend on exogenous attentional withdrawal and target localization. Attention, Perception, \& Psychophysics, 73, 1790-1814.

Taylor, T. L., \& Fawcett, J. M. (2012). Does an instruction to forget enhance memory for other presented items? Consciousness \& Cognition, 21, 1186-1197.
Thompson, K. M., Hamm, J. P., \& Taylor, T. L. (2014). Effects of memory instruction on attention and information processing: Further investigation of inhibition of return in item-method directed forgetting. Attention, Perception, \& Psychophysics, 76, 322-334.

Tolin, D. F., Hamlin, C., \& Foa, E. B. (2002). Directed forgetting in obsessive-compulsive disorder: Replication and extension. Behaviour Research and Therapy, 40, 793-803.

van Hooff, J. C., \& Ford, R. M. (2011). Remember to forget: ERP evidence for inhibition in an item-method directed forgetting paradigm. Brain Research, 1392, 80-92.

Wickham, H. (2009). ggplot2: Elegant graphics for data analysis. New York, NY: Springer.

Wickham, H. (2011). The split-apply-combine strategy for data analysis. Journal of Statistical Software, 40, 1-29. Retrieved from http:// www.jstatsoft.org/v40/i01/

Wickham, H. (2017a). stringr: Simple, consistent wrappers for common string operations (Package Version 1.2.0) [Computer software]. Retrieved from https://CRAN.R-project.org/package=stringr

Wickham, H. (2017b). tidyr: Easily tidy data with spread() and gather() functions (R Package Version 0.6.3) [Computer software]. Retrieved from http://CRAN.R-project.org/package=tidyr

Wickham, H., \& Francois, R. (2016). dplyr: A grammar of data manipulation (R Package Version 0.5.0) [Computer software]. Retrieved from http://CRAN.R-project.org/package=dplyr

Wilhelm, S., McNally, R. J., Baer, L., \& Florin, I. (1996). Directed forgetting in obsessive-compulsive disorder. Behaviour Research and Therapy, 34, 633-641.

Wong, A. C., \& Moulds, M. L. (2008). Depressive rumination and directed forgetting: An examination of encoding style. Cognitive Therapy and Research, 32, 1-10.

Wylie, G. R., Foxe, J. J., \& Taylor, T. L. (2008). Forgetting as an active process: An fMRI investigation of item-method directed forgetting. Cerebral Cortex, 18, 670-682.

Yang, W., Liu, P., Cui, Q., Wei, D., Li, W., Qiu, J., \& Zhang, Q. (2013). Directed forgetting of negative self-referential information is difficult: An fMRI study. PLOS ONE, 8(10), e75190.

Yang, W., Liu, P., Xiao, X., Li, X., Zeng, C., Qui, J., \& Zhang, Q. (2012). Different neural substrates underlying directed forgetting for negative and neutral images: An event-related potential study. Brain Research, 1441, 53-63. 